\title{
Isotopic exchange method for preparation of io-dine-125-n-(1-p-nitrobenzaldhydephenyl)-2- (2-iodophenyl)-4-(4-nitrobenzilidene)-imidazolin -5-one and its biological evaluation
}

\author{
Atteyat A. Labib \\ Nutrition Depart. College of Designs and Home Economy, Qassim University, Bldg. 3897, Buraydah 52383-8314, Saudi Arabia \\ Inshas Cyclotron, Experimental Nuclear Physics Department, Nuclear Research Center, EAEA, Cairo 13759, Egypt \\ *Corresponding author E-mail: Atteyatal.Labib@gmail.com
}

Copyright $\odot 2014$ Atteyat A. Labib. This is an open access article distributed under the Creative Commons Attribution License, which permits unrestricted use, distribution, and reproduction in any medium, provided the original work is properly cited.

\begin{abstract}
N-(1-p-nitrobenzaldhydephenyl)-2-(2-iodophenyl)-4-(4-nitrobenzilidene)-imidazolin-5-one was labeled with radioactive iodine-125.via nucleophilic substitution reaction, the isotopic exchange labeling process was carried out in dry state at $330 \mathrm{oC}$ for $20 \mathrm{~min}$. The radiochemical yield was determined by using electrophoresis and the yield is equal to $93 \%$.Ammonium sulphate was used as catalyst to facilitate the exchange reaction in melt state. Maximum heated with iodine-125 at $330 \mathrm{oC}$ for $20 \mathrm{~min}$ in a reaction mixture with $\mathrm{pH}$ between 6 and 8 . The results referred to the importance of use $\mathrm{NaOH}$ in a molarity of less than $0.02 \mathrm{M}$ to prevent the decomposition of the produced tracer due to the change in $\mathrm{pH}$ of the reaction mixture. The biodistrubution pattern of the labeled compound was examined in normal as well as in tumor bearing mice and the data show high clearance from the blood as the activity remind in the blood $11.2 \%$ at 4 hours post injection. The labeled compound was extracted via liver as the accumulated activity in the liver and intestine were $14.4,15.4 \%$ respectively at 4 hours post injection The biodistrubution of labeled compound in tumor bearing mice accumulation in ascites with high percentage equal to $55.3 \%$ at 24 hours post injection. This demonstrate the ability of this tracer concentrate in tumor site which primate its possible application as therapeutic agent.
\end{abstract}

Keywords: Imidazoline Derivatives, Isotopic Exchange Method, Tumor Targeting, Tissues Distribution.

\section{Introduction}

The nitroimidazole derivatives such as misonidazole and metronidazole have been shown to enhance the radio sensitivity of hypoxic cells. These compounds are also known to exert a toxic effect selectively on hypoxic cells. The hypo- xic cell toxicity may arise from the formation of reactive reduction products of the nitro compounds. Also, several imidazole derivatives have been developed as diagnostic agents for positron emission tomography (PET) or optical imaging [1-4]. Many imidazolines are biologically active [5, 6]. 2-imidazolines have been investigated as antihyperglycemic, anti-inflammatory, antihypertensive, antihypercholesterolemic, and antidepressant reagents[6, 7]. The imidazole nucleus appears in a number of naturally occurring products among which, the most important are the amino acid, histidine, the purines which comprise many of the important bases in nucleic acids and hydration which occurs in beet sap. Also, In recent years, different imidazole and benzoimidazole drugs have been found to be associated with several biological activities such as antiparasitic, antifungal, anti-inflammatory, antibacterial activities [8], [9]. imidazole derivatives are reported to exhibit a wide range of pharmaceutical bactericidal[8] activities. 5nitroimidazole (azomycine) is active against infections associated with anaerobic conditions. Subsequently, it was shown that changing the substitution pattern from the 5-nitro in nitroimidazole to the2-nitro in misonidazole (M1SO) increases the reduction of the molecule under slightly aerobic conditions. These compounds enter cells by diffusion. In the cytoplasm, the nitro group (NO2) undergoes one-electron enzymatic reduction to the free radical anion. In normoxic cells, this reaction step in reversed by intercellular oxygen, and the oxidized molecule diffuses out of the cell. In 
hypoxic tissue, the free radical is further reduced to a reactive species, hydroxylamine and then to an amine free radicals are attached irreversibly to cellular macromolecules and are retained within the cell. Reduction of these molecules occurs in all tissues with viable enzymatic processes, hut retention occurs only in those tissues with low oxygen tension. In addition, radioiodinated imidazoline compounds were used in nuclear medicine[9]. In view of these findings, the author planned to synthesis imidazolinone derivative containing iodine atom in their structure then labeled with iodine $\left({ }^{125} \mathrm{I}\right)$. The optimum conditions required to produce high labeling yield with high purity was studied. In-vivo study of the labeled compound in non-tumor and tumor bearing mice was done to elucidate its biological behavior.

\section{Experimental}

\subsection{Materials}

Melting point was determined in an open capillary and is uncorrected. The IR spectrum was recorded on pyeunicam sp11100 spectrophotometer. Mass spectrum was performed by a shimadzu Gc-MS-QP 100 Ex (shimadzu, Japan) Elemental analysis were carried out the Microanalytical Research Center, Faculty of Science, and Cairo University. All other chemicals were purchased from Merck Co. Radioactive iodine-125 was purchased from Institute of Isotopes Co. Ltd. (IZOTOP) Budapest, Hungary.

\subsection{Procedures}

N-(1-p-nitrobenzaldhydephenyl)-2-(2-iodophenyl)-4-(4-nitrobenzilidene) imidazolin-5-one was synthesized according to the procedure a solution of 1-(4- aminophenyl)-2(2-iodophenyl)-4-(4-nitrobezylidine)2-imidzolin-5-one (0.01mol) and p-nitrobenzaldehyde $(0.01 \mathrm{~mole})$ in acetic acid $(30 \mathrm{ml}$.) containing freshly fused sodium acetate $(0.01 \mathrm{~mole}$.) was refluxed for 2 hours. The precipitate was collected, and the solid obtained was crystallized from DMF as yellow crystals, (m.p 330-332 $2^{\circ} \mathrm{C}$, yield $55 \%$ ) as illustrate in figure 1. The structure was confirmed by I.R. Spectrum which revealed bands at $1655 \mathrm{~cm}-1(\mathrm{C}=\mathrm{O})$, and $1621(\mathrm{C}=\mathrm{N}) .1 \mathrm{H}-\mathrm{NMR}$ spectrum of [46a, DMSO- d6] afforded signals at $\delta$ 3.87ppm (s, 3H, OCH3), $7.00(\mathrm{~s}, 1 \mathrm{H}$, methylene) and 7.12-8.32 (m, 16H, Ar-H) and 9.88 (s, 1H, CH=N).
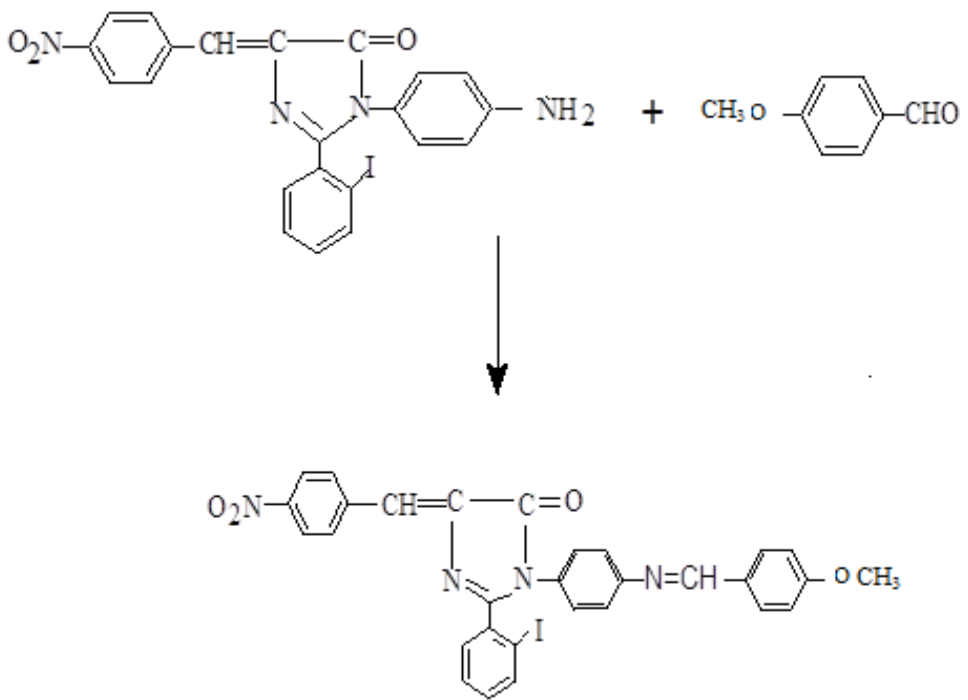

Fig. 1: Synthesis scheme of N-(1-p-nitrobenzaldhydephenyl)-2-(2-iodophenyl)-4-(4-methoxybenzilidene) imidazolin-5-one

\subsection{Labeling technique}

Labeling in dry state was carried out in a V shaped bottom vial with a screw cap. Radioactive sodium iodide [5 $\mu$, $100 \mu \mathrm{Ci}$ ] was introduced in the reaction vial and evaporated to dryness by a vacuum line, thereafter $5 \mathrm{mg}$ of imidazoline was added, and the reaction vial was closed and put in a sand bath at $300^{\circ} \mathrm{C}$. After a defined time the reaction was stopped by cooling the vial within an ice bath. The reaction mixture was dissolved in $150 \mathrm{ml}$ dimethyl formamide for analysis.

\subsection{Determination of radiochemical purity of imidazoline 5-one.}


The radiochemical purity was determined using the electrophoresis technique (EC 3000P-series 90 programmable (E-C apparatus corporation) power and chamber supply units using cellulose acetate strips. Cathode and anode poles and application points were indicated on cellulose acetate strips and these strips were moistened by buffer solution [0.05 $\mathrm{M}$ phosphate of $\mathrm{pH}$ 7]. They were putted in electrophoresis chamber after the samples set on the strips [5 $\mu \mathrm{l}]$. Standing time and applied voltage for one and half-hour at 300 volts Developed strips were dried and cut into $1 \mathrm{~cm}$ segments. They were counted by a well-type $\mathrm{NaI}(4 \% \mathrm{Tl})$ scintillation counter. The radio-histogram of the labeled compound was presented in figure 2 .

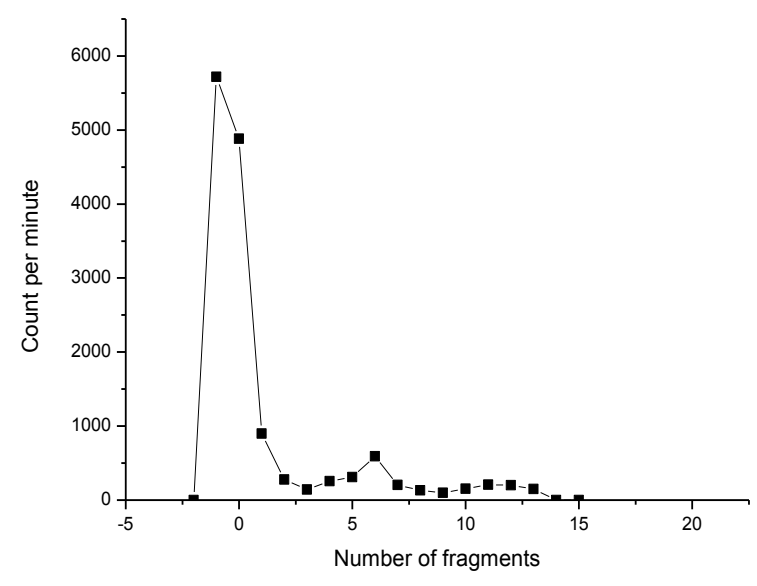

Fig. 2: Paper Electrophoresis Pattern of N-(1-p-nitrobenzaldhydephenyl)-2-(2-iodophenyl)-4-(4-nitrobenzilidene) imidazolin-5-one

\subsection{Tumor implementation}

$2.2 \times 106$ cells $(200 \mu \mathrm{l})$ of Erlich culture were implemented in the left leg of female Swiss Albino mice. The tumor volume was read every 3 days, until it reached $100 \mathrm{~mm} 2$ as an example of hypoxic tumor. For non-hypoxic tumor, the same cell count was injected intraprotenial and the mice were kept for 10 days on normal diet in a metabolic cage until the growth was appeared.

\subsection{Bio distribution studies}

This experiment was done by diluting the neutral solution of the labeled imidazoline-one with $1 \mathrm{ml}$ saline for injection , and filtered through $0.22 \mu \mathrm{m}$ Millipore filter into a sterile sealed vial.100 $\mu 1(250-300 \mathrm{KBq})$ was injection, in the tail vein of the healthy and tumor bearing Albino mice, weighing approximately $25 \mathrm{~g}$ each (3groups each of 3 mice). The mice were maintained on normal diet in a metabolic cage. The mice were sacrificed at $2 \mathrm{~h}$ and $4 \mathrm{~h}$ post injection and in addition at $24 \mathrm{~h}$ in the case of tumor bearing mice. Samples of fresh blood, bone and muscle were collected in preweighing vials and counted.The different organs were removed, counted, and compared to the standard solution of the labeled imidazoline -5-one. The average percent values of the administrated dose/organ were calculated. Blood, bone and muscles were assumed to be 7,10 and $40 \%$ of the total body weight, respectively

\section{Results and discussion}

N-(1-p-nitrobenzaldhydephenyl)-2-(2-iodophenyl)-4-(4-nitrobenzilidene) imidazolin-5-one compound can be labeled with radioactive iodine through nucleophilic substitution reaction. This exchange reaction can be done in melt state . In melt state, the imidazolin-5-one compound must be stable at its melting point and has a high dielectric constant to dissolve the radioiodine. In our study imidazolin-5-one was labeled with radioactive iodine in melt state, and the factors that affect the labeling reaction were studied. The results of this study can be presented as follow.

\subsection{Effect of Substrates Content}

The dependence of ${ }^{125} \mathrm{I}$ - imidazolin-5-one yield on the amounts of imidazolin-5-one was studied. The results of this study are summarized in figure. (3), The data represented in the figure clearly show that both reaction yields and velocity increased with increasing the amount of imidazolin-5-one.The optimum amount of imidazolin-5-one sufficient to give radiochemical yield more than $93 \pm 2.2 \%$ was $5 \mathrm{mg}$ when the reaction mixture was heated up to $330^{\circ} \mathrm{C}$ for 10 min. By increasing the time of heating up to $60 \mathrm{~min}$. the radiochemical yield increased slowly by $5 \%$. This can be explained as $5 \mathrm{mg}$ when melted, it gives volume enough to react with active iodine. Also figure 3 . Show that 
imidazolin-5-one compound more reactive for radioiodination which may be due to the presence of NO2 group which is more electrondonner than $\mathrm{CHO}$ group.

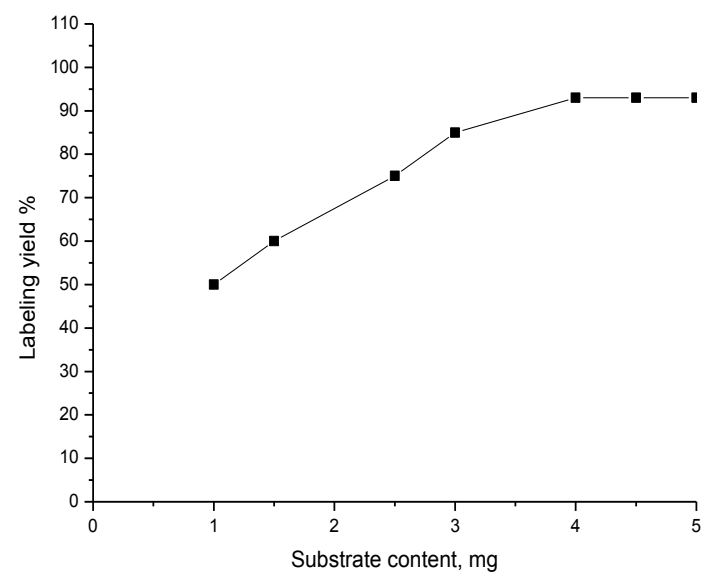

Fig. 3: Effect of imidazoline-5-one amount on the

Percent labeling yield of ${ }^{125} \mathrm{I}$-imidazoline-5-one; reaction condition: $\mathrm{X}$ mg imidazoline, $5 \mu 1 \mathrm{Na}^{125} 1$, $\mathrm{pH}$ between 6 and 8 and reaction temperature $330^{\circ} \mathrm{C}$.

\subsection{Effect of $\mathrm{pH}$}

The hydrogen ion concentration of the reaction mixture has a dramatic effect on the labeling of imidazolin-5-one with iodine-125 .Figure 4. Represent the data obtained from experiments. The data shows that the nucleophilic substitution reaction for imidazolin-5-one proceeded well around $\mathrm{pH}$ 6-8 giving radiochemical yield that exceeds $93 \pm 2.2 \%$.

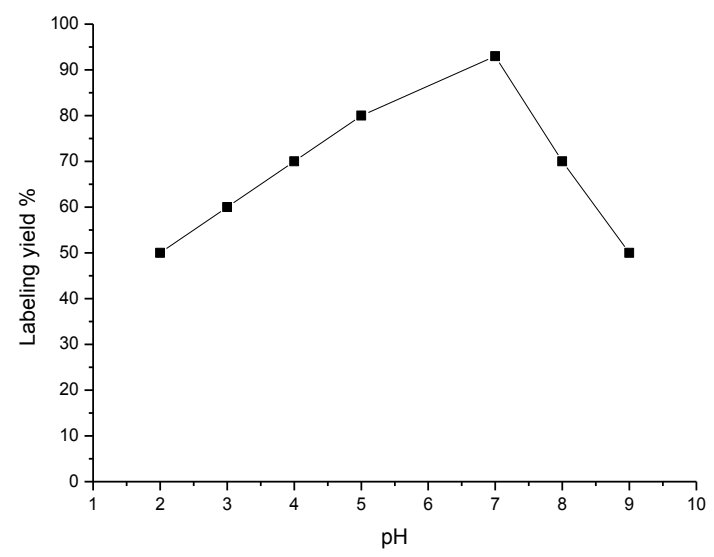

Fig. 4: Variation of the ${ }^{125}$ I-imidazoline-5-one yield as a function of $\mathrm{pH}$; reaction condition: $4 \mathrm{mg}$ imidazoline, $5 \mu 1 \mathrm{Na}^{125} 1$, at different $\mathrm{pH}$ values and reaction temperature $330^{\circ} \mathrm{C}$.

\subsection{Effect of reaction temperature}

The ${ }^{125} \mathrm{I}$ imidazolin-5-one was prepared by an exchange reaction between radioiodine and the inactive one in the iodocompound in which iodine is bound to an aromatic carbon atom. The reaction proceeds by nucleophilic substitution of iodine atom via an intermediate where both radioactive and non-radioactive iodine atoms are symmetrically bound to the same carbon. The velocity of the reaction depends on the rupture of the C-1 bond which is dependent on the temperature. 


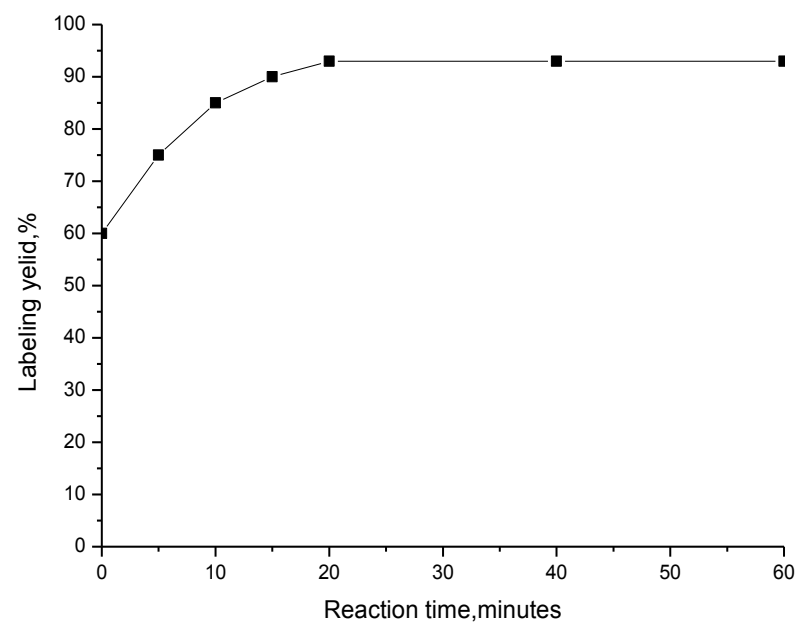

Fig. 5: Variation of the ${ }^{125} \mathrm{I}$-imidazoline-5-one yield as a function of reaction time; reaction condition: $4 \mathrm{mg}$ imidazoline,5 $\mu 1 \mathrm{Na}{ }^{125} \mathrm{I}$, at $\mathrm{pH} 7$. The reaction mixture was heated at $330^{\circ} \mathrm{C}$ for different reaction time.

There is a significant effect of temperature on the rate of this exchange reaction as cleared from figure 5. When the reaction was done at $330^{\circ} \mathrm{C}$, the yield of ${ }^{125} \mathrm{I}$ - imidazolin-5-one was $\sim 93 \%$ after 10 min reaction time. When the reaction temperature was decreased to $25^{\circ} \mathrm{C}$, the yield of ${ }^{125} \mathrm{I}$ - imidazolin-5-one was very poor and not exceeds $20 \%$ even when the reaction time was extended to $50 \mathrm{~min}$ as cleared from figure 5 . These findings can be explained, as in any chemical reaction the reactants must be in good contact with each other, so in melt state the reactants must be completely melted.

\subsection{Effect of added amounts of ammonium sulphate catalysis}

Depending on the fact that catalysis enhance the reaction toward product formation and can be reduce time of the reaction and also decrease the kinetic energy required to attain maximum yield, The use of ammonium sulphate as a catalysis arise from its role in the formation of $\mathrm{H}_{2} \mathrm{SO}_{4}$ as the result of its in-situe decomposition, that control the acidity of the reaction medium. Figure.6. represent the data obtain from the use of ammonium sulphate as a catalyst. In the labeling of imidazoline 5-one with iodine-125. The data clearly show that, the use of $5 \mathrm{mg}$ of ammonium sulphate was sufficient to give yield more than $93 \pm 2.2 \%$ of ${ }^{125} \mathrm{I}$ - imidazoline 5-one. By increasing the quantity of ammonium Sulphate, the yield decreased drastically to less than $50 \%$ for both labeled compounds. This data can be explained as follow, in low concentration of ammonium sulphate $(5 \mathrm{mg})$, its dissociation is complete and become sufficient to attain the desired acidic $\mathrm{pH}$ required to proceed the reaction well and also the formation of volatile iodine is minimized. While in the case of large concentration of ammonium sulphate, the dissociation is reduced and also the formation of volatile iodine increased leading to poor radiochemical yield. The observed decrease in the radiochemical yield with the increase of ammonium sulphate was found in good agreement with the result obtained earlier on the labeling of $15 \mathrm{p}$ iodophenyl pentadecanoic acid and on the labeling of other iodoaromatics.

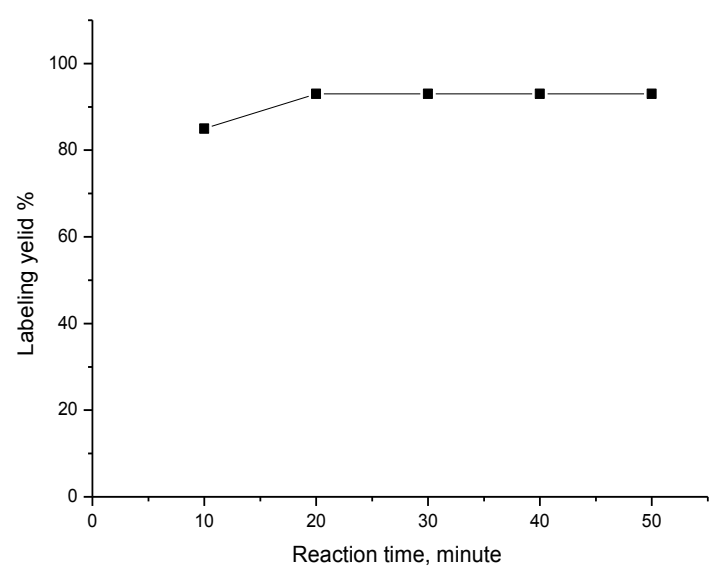

Fig. 6: Variation of the ${ }^{125}$ I-imidazoline-5-one yield with time as a function of the amount of ammonium sulphate in dry state; reaction condition: 4 mg Imidazoline, $5 \mu 1 \mathrm{Na}^{125} \mathrm{I}, 5 \mathrm{mg}$ amm.sulphate, at $\mathrm{pH}$ 7.The reaction mixture was heated at $330^{\circ} \mathrm{C}$ for different reaction time. 


\subsection{Effect of base}

Because $\mathrm{Na}^{125} \mathrm{I}$ soluble in sodium hydroxide solution, the effect of the molarity of $\mathrm{NaOH}$ on the percent yield of ${ }^{125}$-I imidazoline 5-one was studied. The test was carried out by adding 0.01 to $0.5 \mathrm{M} \mathrm{NaOH}(10 \mu \mathrm{l})$ to the $\mathrm{Na}^{125} \mathrm{I}$ in the reaction vial and the solution was evaporate under a vacuum, then the substrate was added. The reaction proceeds as usual; the data obtained was summarized in figure 7 . Which show that $\mathrm{NaOH}$ solution had a marked deleterious effect on the labeling of imidazoline 5-one with iodine-125 even at molarity less than 0.02. By increasing the molarity of added $\mathrm{NaOH}$ up to 0.5 the yield of the labeled compounds decreased markedly to $\sim 70 \%$. This assures the necessity to keep sodium Hydroxide molarity as low as possible.

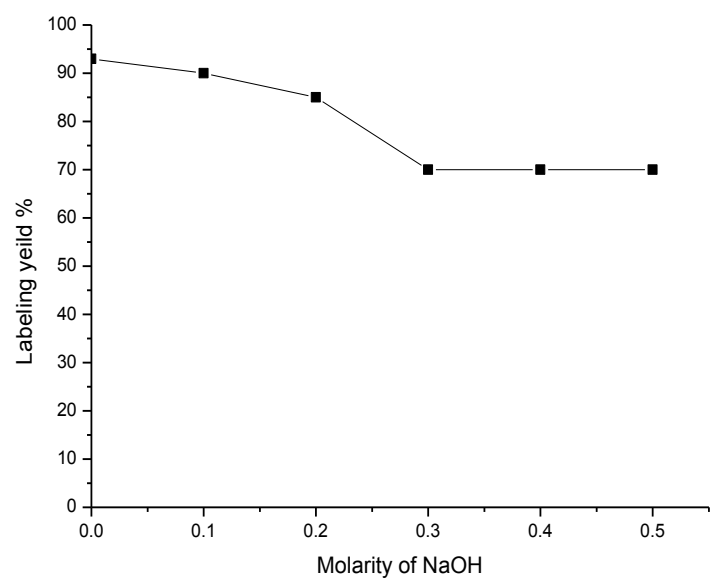

Fig. 7: Variation of the125I-imidazoline-5-one yield at different $\mathrm{NaOH}$ Molarities ; reaction condition: $4 \mathrm{mg}$ imidazoline, $5 \mu 1 \mathrm{Na}{ }^{125} 1, \mathrm{x} \mu 11 \mathrm{M} \mathrm{NaOH}$, at $\mathrm{pH}$ between $6-8$ and reaction temperature at $330^{\circ} \mathrm{C}$.

\subsection{Biological study}

The biological distribution pattern as well as the ability of the compound imidazoline 5-one to localized in cancer site and carry the radiotherapeutic nuclide iodine-125 to cancer site are examined in mice as described in recent literature [13]. The mice were injected intravenous with $0.1 \mathrm{ml}$ of the tracers. The bio-distribution of ${ }^{125} \mathrm{I}$ - imidazoline 5-one tracer in normal mice was presented in table 1 . Its clearance from the blood is high as the percentage reaches to $\sim 11.2 \pm 1.8 \%$ at 4 hours post injection. The high liver uptake of the tracer was attributed to their high lipophelicity. This finding was supported by determination of the octanal /saline partition coefficient as its equal to 78. Because the excretion route of the tracer was done via liver, the intestine content increased by time from $9.1 \pm 1.2$ to $15.4 \pm 2.2 \%$ at 2 and 4 h. post injection receptively. Also, some ratios of this compound were excreted through the kidney, as activity detected in urine was 16.7 \pm 2.4 . Otherwise, the uptakes of other organs (bone, muscle, lung, heart, and spleen) are with in normal values. The in-vivo decomposition of this tracer can be seen as the thyroid uptake increased by time from $1.4 \pm 0.2 \%$ to $3.4 \pm 0.9$ $\%$ at $4 \mathrm{~h}$ post injection.

Table 1: Bio-distribution of ${ }^{125} \mathrm{I}$ - imidazoline5-one in normal mice Vial content: $4 \mathrm{mg}$ of imidazoline-5-one, $5 \mu 1 \mathrm{Na} 125 \mathrm{I}, 200 \mu 1 \mathrm{DMF}$, at pH between 6 and 8 and reaction temperature $=330^{\circ} \mathrm{C}$

\begin{tabular}{llc}
\hline Organ or body fluid & \multicolumn{2}{c}{ Time after injection } \\
\hline Blood & $2 \mathrm{~h}$ & $11.2 \pm 1.8$ \\
Bone & $16.4 \pm 2.2$ & $0.9 \pm 0.4$ \\
Muscle & $1.4 \pm 0.2$ & $0.6 \pm 0.2$ \\
Liver & $0.2 \pm 0.9$ & $14.4 \pm 2.6$ \\
Lung & $2.7 \pm 15.4$ & $1.1 \pm 0.5$ \\
Heart & $0.1 \pm 0.4$ & $1.1 \pm 0.4$ \\
Intestine & $0.2 \pm 0.6$ & $15.4 \pm 2.2$ \\
Spleen & $9.1 \pm 1.2$ & $1.1 \pm 0.4$ \\
Stomach & $0.4 \pm 0.02$ & $9.1 \pm 1.5$ \\
Kidney & $13.4 \pm 1.9$ & $2.4 \pm 1.2$ \\
Collected-urine & $4.1 \pm 1.2$ & $16.7 \pm 2.4$ \\
Thyroid & $10.4 \pm 1.2$ & $3.4 \pm 0.9$ \\
\hline
\end{tabular}


Table 2: Bio-distribution of ${ }^{125} \mathrm{I}$ - imidazoline5-one tumor-bearing mice Vial content: $4 \mathrm{mg}$ of imidazoline-5-one,5 $\mu 1 \mathrm{Na}{ }^{125} \mathrm{I}, 200 \mu \mathrm{LMF}$ at $\mathrm{pH}$ between 6 and 8 and reaction temperature $=330^{\circ} \mathrm{C}$.

\begin{tabular}{llcc}
\hline \multirow{2}{*}{ Organ or body fluid } & \multicolumn{3}{c}{ Time after injection } \\
\hline Blood & $2 \mathrm{~h}$ & 4 min. & $24 \mathrm{~h}$ \\
Bone & $6.4 \pm 2.1$ & $3.2 \pm 1.8$ & $1.3 \pm 0.1$ \\
Muscle & $2.4 \pm 0.2$ & $2.6 \pm 0.2$ & $0.3 \pm 0.1$ \\
Liver & $1.6 \pm 0.1$ & $0.6 \pm 0.2$ & $0.0 \pm 0.0$ \\
Lung & $9.4 \pm 2.5$ & $9.2 \pm 1.2$ & $0.3 \pm 0.1$ \\
Heart & $0.4 \pm 0.1$ & $0.5 \pm 1.1$ & $0.0 \pm 0.0$ \\
Intestine & $0.2 \pm 0.2$ & $0.3 \pm 1.1$ & $3.3 \pm 0.9$ \\
Spleen & $9.1 \pm 1.2$ & $7.1 \pm 2.2$ & $0.9 \pm 2.1$ \\
Stomach & $0.3 \pm 0.5$ & $0.2 \pm 0.3$ & $0.8 \pm 0.1$ \\
Kidney & $4.4 \pm 0.9$ & $1.1 \pm 0.5$ & $0.7 \pm 0.1$ \\
Collected-urine & $0.3 \pm 1.2$ & $0.1 \pm 0.2$ & $6.3 \pm 2.1$ \\
Thyroid & $3.4 \pm 1.2$ & $5.7 \pm 2.4$ & $0.2 \pm 0.1$ \\
Ascites fluid & $1.0 \pm 0.2$ & $0.4 \pm 0.9$ & $55.3 \pm 0.6$. \\
\hline
\end{tabular}

The bio-distribution of ${ }^{125}$ I-imidazoline 5-one in tumor bearing mice was examined and the data was presented in table 2. The uptake of the tracer in bone, muscle, lungs, heart, and spleen are similar to that of normal mice. Also, the increased uptake of liver, kidneys is due excretion pathway of these tracers. Total ascites weight represent $50.3 \pm 0.1 \%$ of the mice body weight catch high activity reaches to $44.3 \pm 0.1 \%$ at $2 \mathrm{~h}$. post injection and increased markedly up to $55.3 \pm 0.6 \%$ after $24 \mathrm{~h}$ post injection. The localization of this tracer with this high percentage in the tumors site for this long period indicates the specificity of this tracer to the tumorized cell. This specificity can be attributed to the following factors; the high metabolic activity of the tumor cells, the high veciencity correlated to the tumor and the presence of high concentration of hydrolytic enzymes.

All the obtained data demonstrate that, the tracer distributed rapidly throughout the body after intravenous injection ( 2 hours) and cleared rapidly through the hepatobiliary system (4 hours). The liver was the organ with highest radioactivity initially and activity was quickly excreted into the intestinal tract. The presence of small activity in the urinary bladder suggests the excretion of the tracers through the kidneys. Also, the biodistribution of the tracer in tumor bearing mice demonstrate the ability of use this tracer as imaging or therapeutic agent for cancer; but many biological studies are required to establish this findings as: examination in-vitro hypoxic tissue and quantitatively determination of how many tissue uptake from this tracer.

\section{Conclusion}

The optimum amount of imidazoline 5-one that is sufficient to give radiochemical yield more than $93 \pm 2.2 \% \mathrm{was} 4 \mathrm{mg}$ when the reaction mixture was heated up to $330^{\circ} \mathrm{C}$ for $20 \mathrm{~min}$ in dry state. The substitution reaction for imidazoline compound was proceeded well when $\mathrm{pH}$ of the reaction medium is in the range of 6-8, At $\mathrm{pH}$ value lower than 6 , the radiochemical yield decreases drastically reaches $-35 \%$ with the formation of precipitate. The reaction temperature plays an important role in this substitution reaction. As the reaction takes place below the melting point $\left(330^{\circ} \mathrm{C}\right)$, the reaction doesn't complete and the yield decreased markedly. Depending on the fact that catalysis enhances the reaction toward product formation ammonium sulphate was added to the reaction mixture. In spite of this the result obtained referred to the role of ammonium sulphate was clear during this substitution reaction, as $5 \mathrm{mg}$ of ammonium sulfate was found sufficient to increase the radiochemical yield. It is also clear from data obtained that $\mathrm{NaOH}$ molarity must be kept low as possible as radiochemical yield decreased markedly to $60 \%$ when the molarity of $\mathrm{NaOH}$ was $0.5 \mathrm{M}$.The biological distributions of $\mathrm{I}^{125}$-imidazoline-5-one showed marked localization in cancer site with percentage more than $55.3 \pm 0.6 \%$ at $24 \mathrm{~h}$-post injection. Also, the data show that the tracer cleared fast from non-target organs, as the percentage of the radioactivity detected in the blood was $1.3 \pm 0.1 \%$ at $24-\mathrm{h}$. post injection

\section{References}

[1] Zha, Z. et al. (2011). Synthesis and evaluation of two novel 2-nitroimidazole derivatives as potential PET radioligands for tumor imaging. Nuclear medicine and biology 38(4), 501-508. http://dx.doi.org/10.1016\%2Fj.nucmedbio.2010.11.001

[2] Williams, J. (1999).The Academy of Radiology Research: the imaging community's advocate for change. Journal of nuclear medicine 40(6), 9N-22N. http://jnm.snmjournals.org/content/40/6/9N.full.pdf+html

[3] Eschmann, S. M. et al. (2005). Prognostic impact of hypoxia imaging with 18F-misonidazole PET in non-small cell lung cancer and head and neck cancer before radiotherapy. Journal of nuclear medicine 46, 253-260.

[4] Nickols, N. G., Jacobs, C. S., Farkas, M. E., and Dervan. P. B. (2007). Improved nuclear localization of DNA-binding polyamides. Nucleic acids research 35, 363-370. http://dx.doi.org/10.1093\%2Fnar\%2Fgk11042 
[5] Harki, D. A., Satyamurthy,N. D., Stout, B., Phelps, M. E., and Dervan, P. B. (2008). In vivo imaging of pyrrole-imidazole polyamides with positron emission tomography. Proceedings of the National Academy of Sciences 105(35), 13039-13044 doi: 10.1073/pnas.0806308105

[6] MacInnes, N., and Duty, S. (2004). Locomotor effects of imidazoline I2-site-specific ligands and monoamine oxidase inhibitors in rats with a unilateral 6-hydroxydopamine lesion of the nigrostriatal pathway. British Journal of Pharmacology 143(8), 952-959 http://dx.doi.org/10.1038/sj.bjp.0706019

[7] Liu, H., and Du, D-M. (2009). Recent advances in the synthesis of 2-imidazolines and their applications in homogeneous catalysis. Advanced Synthesis \& Catalysis, 351(4), 489-519. http://dx.doi.org/10.1002/adsc.200800797

[8] Graczyk, P. P., Khan, A., Bhatia, G. S., Palmer, V. Medland, D. and Numata, H. (2005). The neuroprotective action of JNK3 inhibitors based on the 6, 7-dihydro-5H-pyrrolo [1, 2-a] imidazoles scafold. Bioorg Med Chem Lett, 15, 4666-4670. http://europepmc.org/abstract/MED/16153829

[9] Uaucu, R., Karaburun, N. G. and Isikdag, I. (2001). Synthesis and analgesic activity of some 1-benzyl-2- substituted-4, 5-diphenyl1Himidazole derivatives. Farmaco, 56, 285-290. http://europepmc.org/abstract/MED/11421256

[10] Bellina, F., Cauteruccio, S., and Rossi, R. (2007). Synthesis and biological activity of vicinal diaryl-substituted 1H-imidazoles. Tetrahedron 63(22), 4571-4624. http://dx.doi.org/10.1016/j.tet.2007.02.075

[11] Kawamura, K. et al. (2010). Imaging of I2-imidazoline receptors by small-animal PET using 2-(3-fluoro-[4-11C] tolyl)-4, 5-dihydro- 1Himidazole ([11C]FTIMD). Nuclear Medicine and Biology 37, p. 625. http://dx.doi.org/10.1016/j.nucmedbio.2010.02.013

[12] Hikasa Y. Mizushima H. (2013). Effects of imidazoline and non-imidazoline $\alpha$-adrenergic agents on rabbit platelet aggregation. Pharmacology 91, 135-144. http://www.karger.com/DOI/10.1159/000346269

[13] Labib A. A. (2013). Synthesis, radioiodination and biodistribution evaluation of 5-(2-amimo-4-styryl pyrimidine-4-yl)-4-methoxybenzofuran6-ol. Asia Oceania Journal of Nuclear Medicine and Biology 1 32, 32-38. http://www.oalib.com/paper/2032386\#.Uy4KjfmSxZ0 